Tropical Journal of Pharmaceutical Research May 2015; 14(5): 907-911

ISSN: $1596-5996$ (print); 1596-9827 (electronic)

(C) Pharmacotherapy Group, Faculty of Pharmacy, University of Benin, Benin City, 300001 Nigeria.

All rights reserved.

Available online at http://www.tjpr.org

Original Research Article

http://dx.doi.org/10.4314/tjpr.v14i5.22

\title{
Knowledge, Attitude and Perception of Physicians towards Adverse Drug Reaction Reporting at King Khalid University Hospital, Riyadh, Saudi Arabia
}

\author{
Mohamed N Al-Arifi*, AY Mayet, Syed Wajid, M Al-Saadi, AEM Idris Salmeen D \\ Babelghaith and FZ Al Ayoubi \\ Clinical Pharmacy Department, College of Pharmacy, King Saud University, Riyadh Saudi Arabia
}

*For correspondence: Email: malarifi@ksu.edu.sa; Tel: +966 0554286827, 0096614677354; Fax: 096614674229

Received: 7 Janaury 2015

Revised accepted: 19 April 2015

\begin{abstract}
Purpose: To assess the knowledge and attitudes of physicians towards adverse drug reaction (ADR) reporting at King Khalid University Hospital, Riyadh, Saudi Arabia.

Method: The study was conducted in King Khalid University Hospital (KKUH), Riyadh, Saudi Arabia over a three-month period (April to June 2014). A self-administered questionnaire was delivered to 116 physicians. The questionnaire comprised of close-ended as well as open-ended questions. Descriptive statistics including, frequency distribution and percentages, were used for both demographic data and various responses to the questions.

Results: The response rate was $81.09 \%$. The mean age of the respondents was $33.3 \pm 11.49$ years. Of the 94 physicians who completed the questionnaire, $88.7 \%$ of them didn't know about the National Pharmacovigilance Center. Almost all the physicians (95.7\%) were not satisfied by their training in ADRs reporting while half $(49.3 \%)$ of the respondents thought that only serious ADRs should be reported.

Conclusion: There is a need for more educational and training programs for physicians regarding the pharmacovigilance system and ADRs reporting. More research is needed to study the knowledge and attitudes of other healthcare professionals and in various settings.
\end{abstract}

Keywords: Health care providers, Pharmacovigilance, Adverse drug reactions, Reporting, Knowledge

Tropical Journal of Pharmaceutical Research is indexed by Science Citation Index (SciSearch), Scopus, International Pharmaceutical Abstract, Chemical Abstracts, Embase, Index Copernicus, EBSCO, African Index Medicus, JournalSeek, Journal Citation Reports/Science Edition, Directory of Open Access Journals (DOAJ), African Journal Online, Bioline International, Open-J-Gate and Pharmacy Abstracts

\section{INTRODUCTION}

In 1969, the WHO [1] defined Adverse Drug Reactions (ADRs) as any noxious unintended reaction to a drug which occur at normal doses used in the prophylaxis, diagnosis or the treatment of diseases. However, according to the International Conference on Harmonisation $\mathrm{ICH}$ guidelines 1996, adverse drug reactions (ADRs) are any harmful unintended response to a drug regardless of the dose [2].
ADRs is a worldwide healthcare problem, in the US several studies have estimated the incidence of ADRs in hospitalized patients ranged from 5.2 - $8.2 \%$, and around $5 \%$ of these incidences resulted in death [3]. The estimated annual cost of adverse drug events (ADE) including ADRs in the US is between 30 billion to 130 billion dollars [ 4 ], this figure accounts only for direct costs of ADRs like increased hospitalization, ER visits and physician visits and does not take into account the indirect costs (i.e., decrease in productivity). In France, an epidemiological study 
of 2067 adults visiting healthcare centers found that $14.7 \%$ of them suffered from adverse drug reactions [5] while in the UK, it was estimated that $6.8 \%$ of hospital admissions were related to ADRs with a projected annual cost of 847 million dollars [6].

In Saudi Arabia, data are still limited, however, in a prospective study the incidence of nonpreventable ADE in a sample of patients admitted to a teaching hospital over 4 months was $6 \%$; with oral anticoagulants as the most frequently implicated drug class[7] . In the same teaching hospital (King Khalid University Hospital) a retrospective study found that $54 \%$ of ADRs were of type $A$ and $39 \%$ of type $B$ [8]. There is a possibility that ADRs are greatly underreported in Saudi hospitals; in two studies it was found that after the implementation of an intensive pharmacovigilance monitoring program for six months in two departments in a university hospital in the western region of Saudi Arabia, ADRs incidence rate detected has risen from 4.5 and $3.1 \%$ the year before the program implementation to 8.2 and $5.1 \%$, respectively, detected during the program $[9,10]$.

The aim of this study was to assess the knowledge and experience of physicians with ADRs reporting and to identify potential factors that may encourage or discourage physicians from reporting ADRs.

\section{EXPERIMENTAL}

\section{Design}

This study used a cross sectional design to evaluate the knowledge, attitude and perception about ADRs among physicians. A total of 116 questionnaires were distributed to physicians by convenience sampling techniques. Copies of the questionnaire were handled to participants either by hand or via the departments' secretaries.

\section{Subjects and setting}

King Khalid University Hospital (KKUH) is the major teaching hospital of the College of Medicine, King Saud University, in Riyadh. It is one of the largest secondary and tertiary care centers in the area, with a capacity of 800 beds. Study participants were physicians working in King Khalid University Hospital (KKUH). The data were collected from April to June 2014 using selfadministered questionnaire. This study was granted ethical approval by the college of medicine king Saud University, Riyadh Saudi Arabia.

\section{Instrument}

The questionnaire consisted of two sections; the first section compiled demographic information and the second segment consisted of 27 questions. Some questions were close-ended and others open-ended. The questionnaire was distributed in both electronic and paper formats to 116 physicians for self-completion. All the paper formats were filled on the spot while those sent electronically were given 2 weeks complete and return, and a single reminder was sent 1 week before the deadline.

\section{Data analysis}

The data from each of the returned questionnaire were coded and entered into Statistical Package for the Social Sciences (SPSS) version 21 software (SPSS Inc, Chicago, IL, USA) which was used for statistical analysis. Accuracy of data entry was assessed by independent, random checking of $10 \%$ of the sample; missing data and blank cells were examined against the original data to identify any discrepancies. Descriptive statistics, including frequency distribution and percentages, were applied to both demographic data and responses to the questions.

\section{RESULTS}

Ninety-four questionnaires were collected giving a response rate of $81.09 \%$. After the exclusion of 22 questionnaires due to missing demographic information, 72 questionnaires remained for statistical analysis. The demographic characteristics of the respondents are summarized in Table 1. The mean age of the respondents was $33.3 \pm 11.49$ years. Majority of survey respondents $(54.8 \%)$ have less than 5 years of experience. General physicians constituted the largest proportion of respondents (43.8\%). Male respondents are $64.4 \%$ while female respondents are only $35.6 \%$.

\section{Knowledge and reporting of ADRs}

Regarding the awareness of ADRs, 63 (87.5 \%) of respondents were aware that not all drugs available in the market were safe and 56 (77.8 $\%$ ) experienced ADRs in patients during their practice. When asked "How many percent of your patients complain about ADRs?" out of 64 participants who answered this question, 54 
$(96.9 \%)$ of them thought that $\leq 20 \%$ of their patients complained about ADRs.

Table 1: Demographic information of physicians

\begin{tabular}{lcc}
\hline Variable & Frequency & $\%$ \\
\hline Age $($ mean \pm SD) & $33.3 \pm 11.49$ & \\
Gender & & \\
Male & 47 & 64.4 \\
Female & 26 & 35.6 \\
Experience & & \\
$0-4$ years & 40 & 54.8 \\
$5-9$ years & 9 & 12.3 \\
$10-14$ years & 9 & 12.3 \\
$15-20$ years & 3 & 4.1 \\
>20 years & 12 & 16.4 \\
Staus/position & & \\
General physician & 32 & 43.8 \\
Specialist & 27 & 37.0 \\
Research & 0 & 0 \\
Academician & 3 & 4.1 \\
Resident & 3 & 4.1 \\
Intern & 6 & 8.2 \\
Others (not specified) & 2 & 2.7 \\
\hline
\end{tabular}

The majority ( $n=60,87 \%$ ) of respondents said that ADRs should be reported by physicians and the Head Department of the institute was the most chosen option for reporting ADRs $(n=22$, $35.5 \%$ ). More than two-thirds ( $n=48,67.6 \%$ ) of respondents said that they will report any ADR whether it is serious, severe or just a mild ADR which cause less inconvenience. However, only $9(12.9 \%)$ of respondents recognized a nearby ADR reporting and monitoring system or center. Only $11.3 \%(n=8)$ and $18.1(n=13)$ knew about the pharmacovigilance program of the SFDA and conceived any difference in awareness of ADR reporting impacted by this system, respectively.

\section{Barriers and factors in ADRs reporting}

When asked "Do you think that pharmacist could be the right person to assist physician in ADR reporting", 61 (85.9\%) of respondent physicians replied affirmatively. There was a general agreement $(n=69,97.2 \%)$ among respondents that $A D R$ reporting and monitoring will benefit patients and the majority ( $n=55,77.5 \%$ ) of them appreciated the contribution of information technologies (i.e. the internet, mobile services) in facilitating ADRs reporting. Most of respondents ( $n=60,84.5 \%$ ) agreed that ADRs reporting should be made mandatory.

However, 29 (41.4\%) of respondents didn't know if there were ADR reporting forms available and $22(31.4 \%)$ answered "No". There was a large dissatisfaction ( $n=41,58.6 \%$ ) by the provided
ADR information and although 62 (87.3 \%) were looking forward to be trained in ADR reporting there was a larger dissatisfaction $(n=67,95.7$ $\%$ ) by the training in ADR reporting. 33 (46.5\%) of respondents were worried about legal issues when writing ADR reports. When asked about the causes of under-reporting of ADRs, the most common reasons chosen by physicians were: "Don't know whom to report" ( $n=32,47.8 \%$ ), "busy schedule" ( $n=25,37.3 \%$ ) and "difficult to pin point suspected drug" ( $n=22,32.8 \%$ ) (Table 2) .However, although "busy schedule" was mentioned by many physician as a reason for under-reporting, only $14(20 \%)$ of them felt that ADR reporting is time consuming activity with no outcome and $58 \%(n=40)$ didn't support "Direct ADR Reporting" by the patients instead of physicians.

Table 2: Reasons cited by physicians for underreporting of ADRs

\begin{tabular}{ll}
\hline Reason & $\mathbf{N}(\%)$ \\
\hline Don't whom to report & $32(47.8)$ \\
Busy schedule & $25(37.3)$ \\
$\begin{array}{l}\text { Difficult to pin point suspected drug } \\
\text { Thinking one report doesn't make a }\end{array}$ & $22(32.8)$ \\
$\begin{array}{l}\text { difference } \\
\text { Insufficient clinical knowledge }\end{array}$ & $20(31.3)$ \\
Lack of incentives. & $15(22.9)$ \\
$\begin{array}{l}\text { Physicians should rather collect data } \\
\text { and publish himself/herself. }\end{array}$ & $12(17.9)$ \\
$\begin{array}{l}\text { Reporting does not influence the } \\
\text { treatment scheme. }\end{array}$ & $11(16.4)$ \\
$\begin{array}{l}\text { ADR is known to physicians. } \\
\text { Only safe drugs are available on the }\end{array}$ & $11(16.4)$ \\
market. & $8(11.9)$ \\
Reporting could show ignorance. & $8(11.9)$ \\
Difficult to admit harm to the patient. & $6(9.0)$ \\
Other reasons. & $1(1.5)$ \\
\hline
\end{tabular}

\section{Experience with ADRs reporting}

Regarding which classes of drugs physicians frequently experienced ADRs with, Antibiotics (not specified) were the most mentioned class of drugs $(n=13,37.1 \%)$ with additional $8.6 \%(n=$ 3 ) of physicians specified vancomycin, 4 (11.4 $\%)$ mentioned steroids and $3(8.6 \%)$ for both statins and non-steroidal anti-inflammatory drugs. Only 34 (47.2\%) of participants answered the question "What are the sources of ADR information to you?", however, out of them 21 $(61.8 \%)$ mentioned the internet as a source compared to $14(29.8 \%), 6(17.6 \%)$ and 1 (2.9 $\%)$ for hard-copy literature, Drug information Center and clinical pharmacist respectively. When asked "Which types of ADRs are usually reported" $49.3 \%$ of respondents $(n=35)$ said that "serious, unexpected and suspected" only should be reported which is more than the 35.2 
$\%(n=25)$ of participants who said that all of the listed types of ADRs should be reported (Table 3 ). Most of physicians ( $n=55,77.5 \%$ ) agreed that patient confidentiality should be maintained in the process of ADRs reporting. $77.5 \%$ of participants $(n=55)$ expected feedback from ADR monitoring centers.

Table 3: Types of ADR often reported

\begin{tabular}{lc}
\hline ADR & $\mathbf{N}(\%)$ \\
\hline Serious unexpected and & $35(37.60)$ \\
suspected & \\
Any ADR of old drug & $4(4.30)$ \\
Any adverse event & $9(9.70)$ \\
ADR to a new product & $10(10.80)$ \\
Only proven ADRs & $3(3.20)$ \\
All of the above & $25(26.90)$ \\
Don't know & $7(7.50)$ \\
\hline
\end{tabular}

\section{DISCUSSION}

ADRs monitoring is an area of pharmaceutical care which deals mainly with the detection, management and reporting of ADRs of drugs which may result from drugs that is taken in normal dose for prophylaxis, prevention or treatment. These adverse drug reactions may range from mere troublesomeness to permanent disability or death $[11,12]$.

Physicians are familiar with ADRs and they generally appreciate the importance of their role in reporting them. However, when it comes to whom to report ADRs; ADR responsible pharmacy staff and medication safety unit is neglected by physicians (however they were not mentioned explicitly in the provided response options but there was the "others" option) and majority of them didn't recognize the hospitallocal or the national ADRs monitoring programs, this finding is similar to the finding of another study $[11,13]$.

There is a general consensus among physicians that ADRs reporting is beneficial and should be mandatory. However, the role of pharmacists and the drug information center is minimized by physicians in favor of information technologies such as mobile applications or the internet and many of them were not familiar with ADRs alert forms provided in the wards, were disappointed by the information provided regarding ADRs and are not exactly sure whom to report these incidents to.

There is also a lot of concern by physicians regarding possible legal consequences of reporting ADRs and some of them think that it's a time consuming process. One study have suggested that physicians generally believe that reporting adverse drug events should be the responsibility of the nurse in charge [14] in addition to fears of loss of anonymity, another study cited the fear of blame as the main reason for not reporting especially amongst junior staff [15]. Many physicians expected feedback on their reports, in one study physicians along with nurses expressed that the provision of feedbacks on reports will likely encourage them to submit them [14].

The drug class with which physicians experience ADRs the most are antibiotics which are known to be amongst the most frequent medications associated with adverse drug events [16]. Almost half of physicians believe that reporting should be reserved only to serious reactions.

The national pharmacovigilance program has only been established recently but it is expected to play a major role in the detection and prevention of adverse drug reactions and in order to achieve this goal it needs the participation of healthcare professionals like physicians who are in the frontline of patient care. However, limited number of studies has been done to assess the knowledge and perception of healthcare professionals toward ADRs reporting and more studies are needed in this regard.

\section{Limitations of the study}

The results of this study should be considered within the context of its limitations. Sampling was done using convenience sampling. Furthermore, there was no pilot study performed prior to this study.

\section{CONCLUSION}

The findings of this study highlight the important role of the medication safety unit and the local pharmacovigilance programs in hospital. Physicians need to be familiarized with the pharmacovigilance program and trained more in ADRs reporting process. This could be done via meetings, seminars and training sessions held by the medication safety unit for which participants could be awarded credit hours as an incentive. Also, regular check-ups of the alert forms stock in the nursing units are needed in order to encourage more ADRs reporting by physicians. More research is needed in various types of healthcare facilities involving a wide range of healthcare professionals to obtain a broader picture. 


\section{ACKNOWLEDGEMENT}

The authors would like to thank Dr Shahzad of Urological Surgical Unit, Ms Melinda Balababa of Pediatric Primary Care Clinic and Ms Anoud Alyahya of Male Primary Care Clinic (all of $\mathrm{KKUH}$ ) for their assistance in data collection.

\section{REFERENCES}

1. International Drug Monitoring: The Role of the Hospital [Internet]. Geneva, Switzerland: World Health Organization; 1969; p 6. [cited 1 December 2014] Available from: http://whqlibdoc.who.int/trs/WHO_TRS_425.pdf

2. Guideline for Good Clinical Practice: an ICH Harmonized Tripartite Guideline [Internet]. International Conference on Harmonisation of Technical Requirements for Registration of Pharmaceuticals for Human Use; 1996; [cited 3 December 2014]. Available from: http://private.ich.org/LOB/media/MEDIA482.pdf.

3. Lazarou J, Pomeranz BH, Corey $P N$. Incidence of adverse drug reactions in Hospitalized patients: a meta-analysis of prospective studies. JAMA. 1998; 279(15): 1200-1205.

4. White TJ, Arakelian A, Rho JP. Counting the costs of drug-related adverse events. Pharmacoeconomic. 1999; 15(5): 445-458.

5. Haddi E, Charpin D, Tafforeau M, Kulling G, Lanteaume $A$, Kleisbauer JP, Vervloet $D$. Atopy and systemic reactions to drugs. Allergy. 1990; 45(3): 236-239..

6. Pirmohamed M, James S, Meakin S, Green C, Scott AK, Walley TJ, Farrar K, Park BK, Breckenridge AM Adverse drug reactions as cause of admission to hospital: prospective analysis of 18820 patients. BMJ. 2004; 329 (7456): 15-19.

7. Aljadhey H, Mahmoud MA, Mayet A, Alshaikh M, Ahmed $Y$, Murray MD, Bates DW. Incidence of adverse drug events in an academic hospital: a prospective cohort study. Int J Qual Health Care. 2013; 25(6): 648-655.
8. Al-Malaq HM, Al-Aqeel SA, Al-Sultan MS. Adverse drug reactions related hospitalization identified by discharge ICD-9 codes in a university hospital in Riyadh. Saudi Med J. 2008; 29(8): 1145-1150.

9. Khan LM, Al-Harthi SE, Saadah OI. Adverse drug reactions in hospitalized pediatric patients of Saudi Arabian University Hospital and impact of pharmacovigilance in reporting ADR. Saudi Pharm J. 2013; 21(3): 261-266.

10. Khan LM, Al-Harthi SE, Saadah OI, Al-Amoudi AB, Sulaiman MI, Ibrahim IM. Impact of pharmacovigilance on adverse drug reactions reporting in hospitalized internal medicine patients at Saudi Arabian teaching hospital. Saudi Med J. 2012; 33(8): 863-868.

11. Adverse Drug Reaction in hospital patients. A systematic review of prospective studies. Bandolier Extra. 2002; pp 1-16.

12. A meta analysis of prospective studies. JAMA. 1998; 279; 1200-1205.

13. Abdel-Latif MM, Abdel-Wahab BA. Knowledge and awareness of adverse drug reactions and pharmacovigilance practices among healthcare professionals in Al-Madinah Al-Munawwarah, Kingdom of Saudi Arabia. Saudi Pharm J. doi:10.1016/j.jsps.2014.07.005

14. Harper M, Helmreich R. Identifying Barriers to the Success of a Reporting System. In: Henriksen K, Battles J, Marks E (Eds). Advances in Patient Safety: From Research to Implementation (Volume 3: Implementation Issues). Rockville, MD: Agency for Healthcare Research and Quality; 2005 [cited 20 December 2014]. Available from: http://www.ncbi. nlm.nih.gov/books/NBK20544/

15. Vincent C, Stanhope N, Crowley-Murphy M. Reasons for not reporting adverse incidents: and empirical study. J Eval Clin Pract. 1999; 5(1): 13-21.

16. Budnitz DS, Pollock DA, Weidenbach KN, Mendelsohn AB, Schroeder TJ, Annest JL. National surveillance of emergency department visits for outpatient adverse drug events. JAMA. 2006; 296(15): 18581866. 